\title{
Mechanical Behaviors of Friction Stir Spot Welded Joints of Dissimilar Ferrous Alloys under Opening-Dominant Combined Loads
}

\author{
Md. Abu Mowazzem Hossain, ${ }^{1}$ Md. Tariqul Hasan, ${ }^{1}$ Sung-Tae Hong, ${ }^{1}$ \\ Michael Miles, ${ }^{2}$ Hoon-Hwe Cho, ${ }^{3}$ and Heung Nam Han ${ }^{3}$ \\ ${ }^{1}$ School of Mechanical Engineering, University of Ulsan, Ulsan 680-749, Republic of Korea \\ ${ }^{2}$ Department of Manufacturing Engineering Technology, Brigham Young University, Provo, UT 84602-9601, USA \\ ${ }^{3}$ Department of Materials Science \& Engineering and Center for Iron \& Steel Research, RIAM, Seoul National University, \\ Seoul 151-744, Republic of Korea \\ Correspondence should be addressed to Sung-Tae Hong; sthong@ulsan.ac.kr
}

Received 9 December 2013; Accepted 19 December 2013; Published 29 January 2014

Academic Editor: Wenya Li

Copyright ( $) 2014 \mathrm{Md}$. Abu Mowazzem Hossain et al. This is an open access article distributed under the Creative Commons Attribution License, which permits unrestricted use, distribution, and reproduction in any medium, provided the original work is properly cited.

\begin{abstract}
Mechanical properties and failure behaviors of friction stir spot welded (FSSW) joints of two dissimilar ferrous alloys, cold-rolled carbon steel (SPCC) and 409L stainless steel (SUS 409L), are investigated under opening-dominant combined loads. The texture of dissimilar FSSW joints depends on the upper sheet material. The failure contours for the FSSW joints under combined loads are constructed in terms of the axial load and shear load by modifying existing failure criteria for resistance spot welds. The shape of the failure contour also depends on the upper sheet material. The failure contours are nearly elliptic in shape when the upper sheet is SPCC and are relatively straight lines when the upper sheet is SUS 409L.
\end{abstract}

\section{Introduction}

Friction stir spot welding (FSSW) is a solid-state joining process that originated from friction stir welding (FSW), a technique patented in 1991 by TWI [1]. Compared with conventional resistance spot welding (RSW), FSSW provides several technical advantages including low energy requirements, fewer problems related to cracking and porosity, less residual stress, and a smaller heat affected zone (HAZ) $[2,3]$. Also, an additional interesting technical advantage over conventional RSW is that FSSW can easily join dissimilar metal alloys.

Even though RSW has been the technique most commonly used in the automotive industries for joining ferrous alloys, RSW is also known to be problematic for several specific ferrous alloys [4]. Moreover, the use of dissimilar ferrous alloys is increasing in the automotive industry to improve the crashworthiness of the automobile structure without significantly increasing weight and manufacturing cost. It is clear that RSW of dissimilar ferrous alloys can be extremely difficult due to the different physical, chemical, and mechanical properties of the base metals [5].

Due to FSSW's technical advantages, including its ability to join dissimilar alloys easily, interest has increased in FSSW as a substitute for RSW in joining similar or dissimilar ferrous alloys in automotive applications. However, even though many pioneering works on FSSW of ferrous alloys have been conducted over the last decade, substituting FSSW for the RSW commonly used in automotive applications will require further investigation. Feng et al. [6] performed an introductory study that examined the feasibility of FSSW of AHSS steel; this study suggested that the mechanical strength of the FSSW joint improves as the width of the bonding ligament increases. Baek et al. [7] examined the effect of tool penetration depth on the microstructures and mechanical properties of FSSW joints of low-carbon steel. Their results showed that the tensile shear strength of low-carbon steel FSSW joint increases as the tool penetration depth increases. Hovanski et al. [8] investigated the microstructure and mechanical 
properties of FSSW joints of hot-stamped boron steel, as well as their failure mechanism: cracking initiated at the interface of the upper and lower sheets and then propagated along the thin ferritic region within weld nugget. Miles et al. [9] investigated the effect of tool wear on joint strength using tools composed of polycrystalline cubic boron nitride $(\mathrm{PCBN})$ and tungsten rhenium (W-Re), where tools with a greater proportion of PCBN were found to provide the best combination of joint strength and wear resistance. Sun et al. [10] experimentally investigated the failure behavior of FSSW joints of mild steel, suggesting based on the result of shear tensile tests, that FSSW joints undergoing fracture by the plug failure mode have higher shear tensile strength compared to FSSW joints undergoing fracture by the interfacial failure mode.

A critical mechanical property of a joint in an automobile body structure is its failure behavior. For RSW, research has been conducted on joint failure, including the development of different fracture models formulated in terms of the local loads acting on the spot welds, as well as in terms of the appropriate strengths of the weld. Chao [11] developed a failure criterion for spot welds and performed strength tests using cross tension and lap shear samples made of high-strength steel. Wung [12] and Wung et al. [13] investigated the failure of spot welds under in-plane torsion and proposed a forcebased failure criterion. Radaj [14], Radaj and Zhang [15], and Zhang [16] adopted a fracture mechanics approach and provided a very detailed description of the stress distribution around a weld nugget. Radaj [14] showed that the fatigue strength of spot-welded joints can be assessed on the basis of the local stress state at the weld spot edge. Radaj and Zhang [15] developed the relations between notch stress and crack stress intensity in the case of plane shear loading (mode II) for the elliptical hole and the blunt crack. Zhang [16] derived approximate stress formulas of structural stress and notch stress for a newly proposed multiaxial spot weld specimen that enables a spot weld to be tested under combined loads ranging from pure shear to pure tension.

The failure behavior of RSW joints under combined or multiaxial loads also has been investigated by many researchers. The failure behavior of a joint under combined loads is typically important in the structural durability and crash safety of the automobile structure. Lee et al. [17] performed a failure test of RSW joints in U-shaped specimens under combined shear and tension loads and proposed an ultimate strength model to fit their experimental results. Lin et al. $[18,19]$ analyzed the failure mechanism of spot welds in square-cup specimens made from mild steel and HSLA steel under combined loads. They proposed a quadratic-form engineering failure criterion in terms of the normalized axial and shear loads with consideration of the sheet thickness and the nugget radius under combined loads. More recently, a different failure criterion in terms of the axial and shear loads has been suggested by Song and Huh [20] to predict the failure behavior of RSW joints.

However, the failure behavior of FSSW joints under combined or multiaxial loads has been rarely investigated until recently, even though the failure behavior of FSSW joints can differ from that of RSW joints [21] due to the different joining
TABLE 1: The chemical compositions provided by the manufacturer and mechanical properties of SPCC and SUS 409L.

(a)

\begin{tabular}{cccccccc}
\hline \multicolumn{8}{c}{ Chemical compositions (wt\%) } \\
& C & Mn & P & Si & S & S-AL & Fe \\
\hline SPCC & 0.0361 & 0.205 & 0.015 & 0.019 & 0.006 & 0.037 & $\begin{array}{c}\text { At } \\
\text { balance }\end{array}$
\end{tabular}

(b)

\begin{tabular}{lccccccccc}
\hline \multicolumn{10}{c}{ Chemical compositions (wt\%) } \\
& $\mathrm{C}$ & $\mathrm{Cr}$ & $\mathrm{Mn}$ & $\mathrm{P}$ & $\mathrm{Si}$ & $\mathrm{S}$ & $\mathrm{Ni}$ & $\mathrm{Ti}$ & $\mathrm{Fe}$ \\
\hline SUS & $\leq 0.03$ & 11.44 & $\leq 1.0$ & $\leq 0.04$ & $\leq 1.0$ & $\leq 0.03$ & $\leq 0.08$ & $\leq 0.75$ & At \\
409L & & & & & & & & & \\
\hline
\end{tabular}

(c)

\begin{tabular}{lccc}
\hline & \multicolumn{2}{c}{ Mechanical properties } \\
& $\begin{array}{c}\text { Tensile strength } \\
(\mathrm{MPa})\end{array}$ & $\begin{array}{c}\text { Yield strength } \\
(\mathrm{MPa})\end{array}$ & $\begin{array}{c}\text { Elongation at } \\
\text { fracture }(\%)\end{array}$ \\
\hline SPCC & 316.8 & 163.8 & 46 \\
\hline SUS & 494 & 236 & 36 \\
409L & 494 & \\
\hline
\end{tabular}

mechanisms of FSSW and RSW. In the present study, the failure behavior of FSSW joints of two dissimilar ferrous alloys under opening-dominant combined loads was investigated experimentally. Based on the experimental result, failure contours for the FSSW joints were constructed in terms of the axial and shear loads. A failure criterion, which was originally developed for RSW joints, was then modified to describe the experimental failure contours of the FSSW joints.

\section{Experimental}

The two dissimilar ferrous alloys used in the present study were $1.2 \mathrm{~mm}$ thick steel sheets of cold-rolled carbon steel (SPCC) and 409L stainless steel (SUS); Table 1 lists the nominal chemical compositions and mechanical properties of these alloys. Cross-sectional samples for microstructure analysis were first prepared from FSSW joints of four different material combinations. The welding was carried out using a convex scrolled shoulder tool made of polycrystalline cubic boron nitride (PCBN)-based composite. The process parameters and tool geometry used to fabricate the FSSW joints are listed in Table 2. During the FSSW process, an argon shroud was introduced using a gas cup located around the tool to minimize the surface oxidation of the joint. The samples were mechanically ground and electrolytically polished in a solution of $10 \mathrm{~mL}$ perchloric acid $+90 \mathrm{~mL}$ ethanol using a Struers Lectropol-5 electrolytic polisher. High-resolution EBSD studies were performed using a Jeol JSM6500F FESEM equipped with an HKL Channel 5 EBSD system. The accelerating voltage was $20 \mathrm{kV}$, the probe current was $4 \mathrm{nA}$, and the working distance was $15 \mathrm{~mm}$, with the sample stage tilted by $70^{\circ}$. The camera resolution was $1000 \times 800$ pixels in the operation of $8 \times 8$ binning. The mapping grid was a regular square with $0.7 \mu \mathrm{m}$ steps. The limits of the low-angle 
TABLE 2: Friction stir spot welding parameters and tool geometry used in the experiments.

\begin{tabular}{|c|c|c|c|c|c|c|c|}
\hline \multicolumn{5}{|c|}{ Process parameters } & \multicolumn{3}{|c|}{ Tool geometry } \\
\hline $\begin{array}{l}\text { Rotation } \\
\text { (rpm) }\end{array}$ & $\begin{array}{l}\text { Plunging rate } \\
(\mathrm{mm} / \mathrm{min})\end{array}$ & $\begin{array}{l}\text { Depth } \\
(\mathrm{mm})\end{array}$ & Control mode & $\begin{array}{l}\text { Dwell time } \\
\quad(\mathrm{sec})\end{array}$ & $\begin{array}{l}\text { Shoulder diameter } \\
\qquad(\mathrm{mm})\end{array}$ & $\begin{array}{l}\text { Pin diameter } \\
(\mathrm{mm})\end{array}$ & $\begin{array}{l}\text { Pin length } \\
(\mathrm{mm})\end{array}$ \\
\hline 1400 & 8 & 1.45 & Servo control & 2 & 36.8 & 5.7 & 1 \\
\hline
\end{tabular}

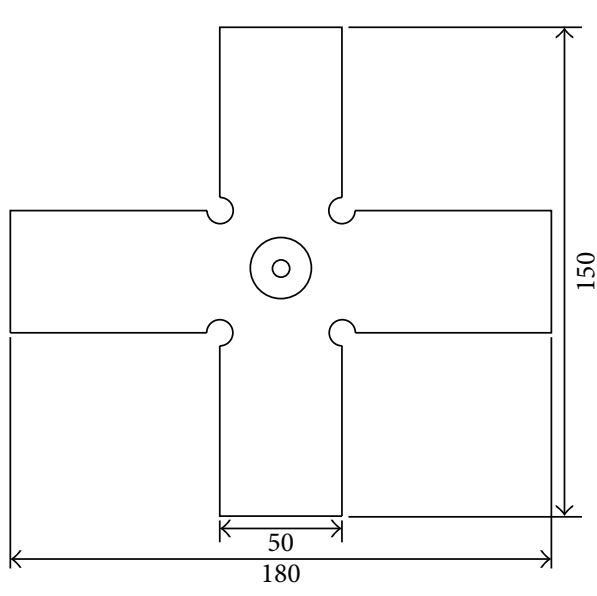

(a)

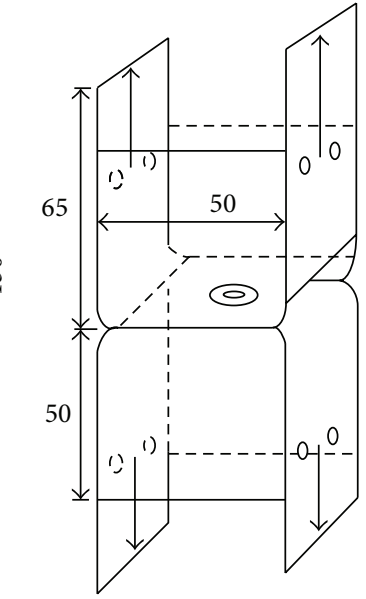

(b)

FIGURE 1: Schematics of fabricated and welded specimens: (a) top view of unfolded square-cup specimen and (b) folded square-cup specimen with FSSW (dimensions in $\mathrm{mm}$ ).

boundaries (LABs) and high-angle boundaries (HABs) were, respectively, set to $2^{\circ}$ and $15^{\circ}$. The grain size was measured using the linear intercept method. The hardness profiles in the stir zone and surrounding regions of the FSSW joints were also measured as a function of distance from the weld center.

Square-cup specimens made of SPCC and 409L SUS were then fabricated; these specimens were then friction stir spot welded as depicted schematically in Figure 1, with four different material combinations: SPCC/SPCC, SPCC (top)/SUS (bottom), SUS (top)/SPCC (bottom), and SUS/SUS. Once again, the welding was carried out using a convex scrolled shoulder tool made of PCBN-based composite with the process parameters listed in Table 2. Note that the four corners of each square-cup specimen were arc-welded to ensure adequate stiffness of the cup specimen under opening-dominant combined loads and to guarantee a relatively uniform loading along the circumference of spot weld.

In order to impose a combined load on the FSSW joint, four fixture sets were designed with different inclined loading angles $\phi$ of $0^{\circ}, 15^{\circ}, 22^{\circ}$, and $30^{\circ}$ (Figure 2), where $\phi$ is the angle between the load application line and the center line of the FSSW joint. In each experimental setup, the welded squarecup specimens were mounted to the fixture set by means of bolts through the specimen holes. The reinforcement plates were attached to the specimen to prevent plastic deformation near the specimen holes during loading. Using the inclined loading angle $\phi$, the applied load $F$ can be simply decomposed into the axial load $F_{N}$ and the shear load $F_{S}$ as

$$
\begin{aligned}
F_{N} & =F \cos \phi, \\
F_{S} & =F \sin \phi .
\end{aligned}
$$

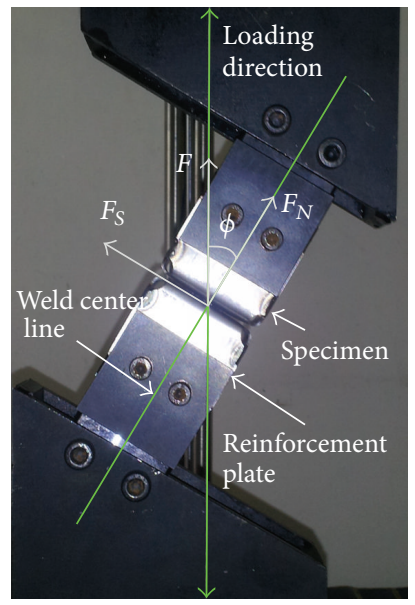

FIgURE 2: Experimental setup for $\phi=30^{\circ}$.

Quasi-static tests of the FSSW joints under combined loads were conducted using a universal testing machine with a displacement rate of $2 \mathrm{~mm} / \mathrm{min}$ along the load application line. During each test the load and displacement were recorded as functions of time. In general, the test was terminated when the FSSW joint was completely separated. The cross section through the weld center of each failed FSSW joint was examined using an optical microscope to understand the failure behavior for each loading condition.

\section{Results and Discussion}

3.1. Microstructures. FSSW joints without visible macroscopic defects were successfully produced with the selected 


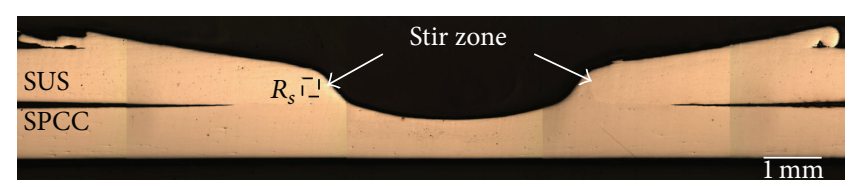

FIGURE 3: A cross-sectional macrograph of a SUS/SPCC FSSW joint.

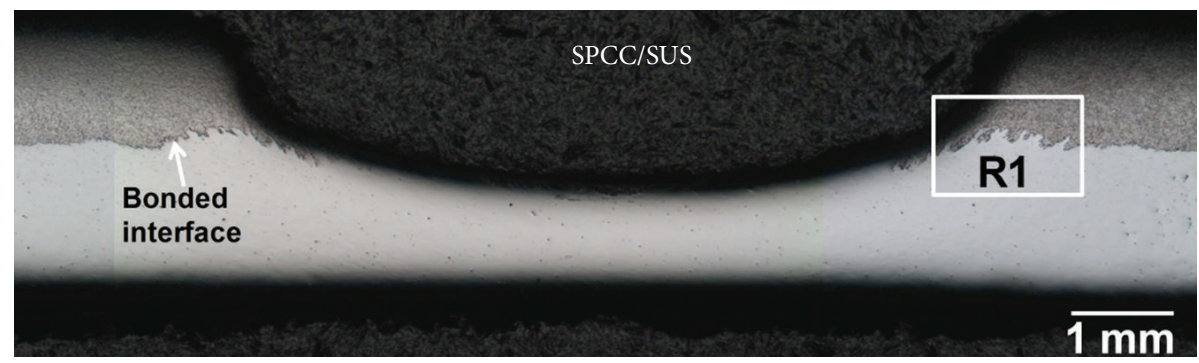

(a)

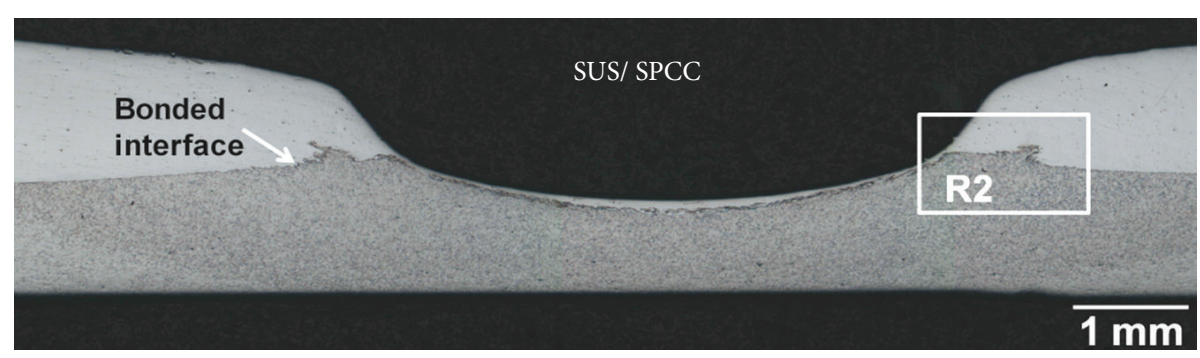

(b)

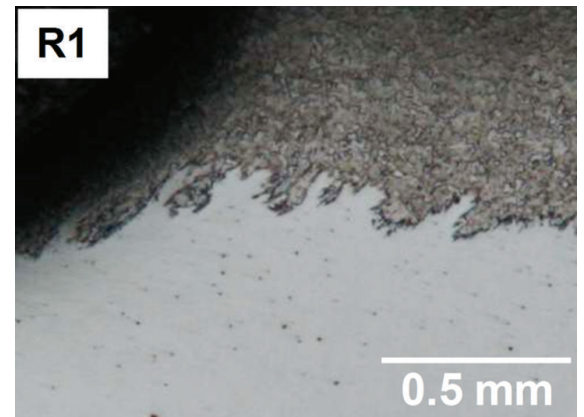

(c)

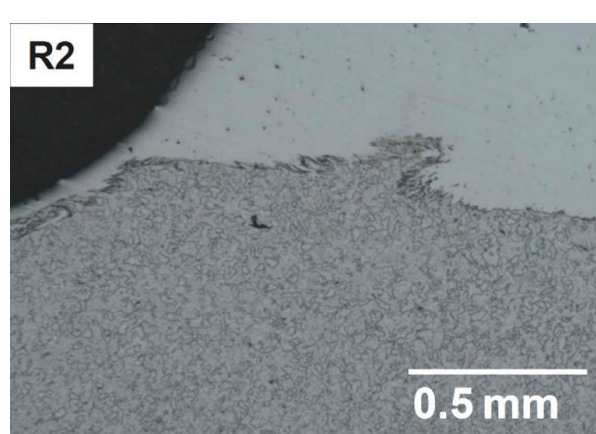

(d)

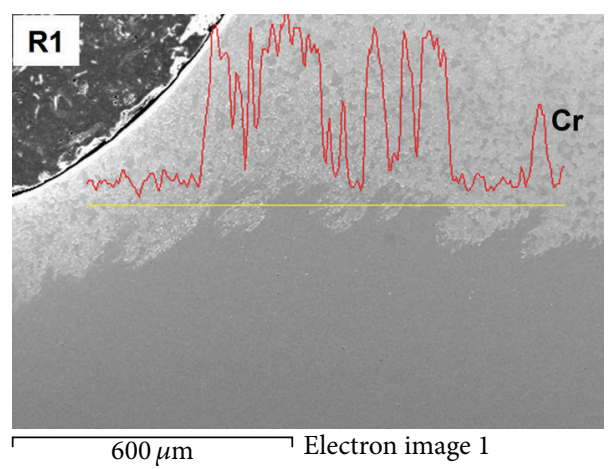

(e)

Figure 4: Optical micrographs of (a) SPCC/SUS and (b) SUS/SPCC FSSW joints; (c) region R1 in (a) and (d) region R2 in (b); (e) Cr distribution profile in region $\mathrm{R} 1$ [21]. 


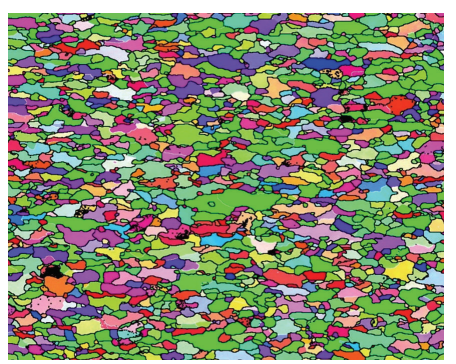

(a)

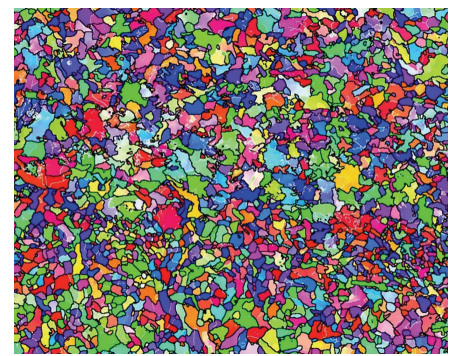

(c)

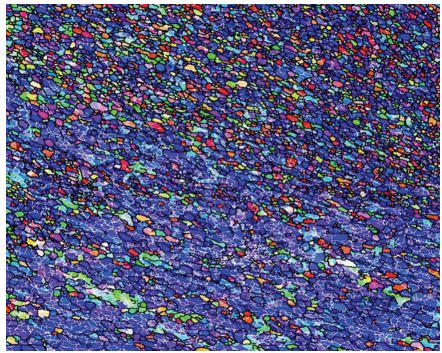

(e)
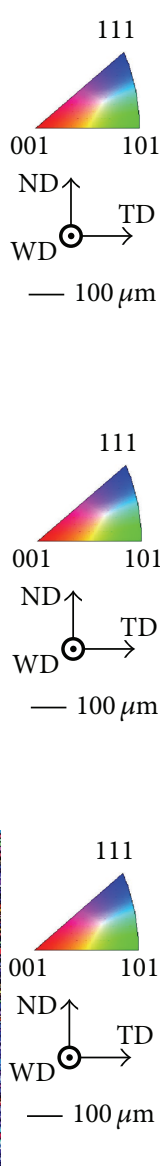

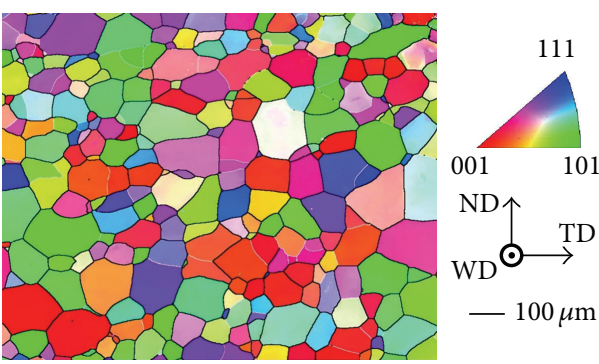

(b)

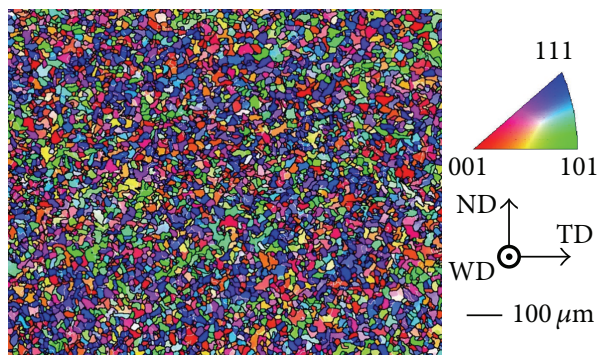

(d)

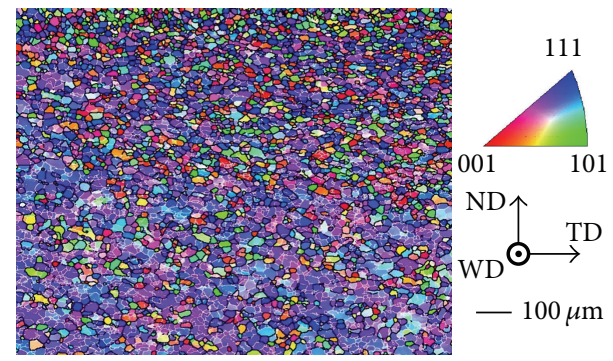

(f)

FIGURE 5: Orientation maps of the base material in (a) SPCC and (b) SUS and the stir zone in (c) SPCC/SPCC, (d) SPCC/SUS, (e) SUS/SPCC, and (f) SUS/SUS, respectively; WD, TD, and ND, respectively, correspond to the welding, transversal, and normal directions.

process parameters for all four material combinations studied, as evidenced by a representative cross-sectional macrograph of SUS/SPCC FSSW joint in Figure 3 [21]. The indentation profile of the joint reflects the shape of the pin and the convex shoulder of the tool. The surface of the tool was examined visually after each weld. There was no significant tool wear observed throughout the entire set of experiments conducted for the present study.

The mixing of materials in the stir zone of dissimilar FSSW joints (SPCC/SUS and SUS/SPCC) was already presented in our previous study [21]. We present the mixing of materials in the stir zone here once again just for the completeness of the study. The mixing of materials in the stir zone of dissimilar FSSW joints depends on the material combination (Figures 4(a) and 4(b)) [21]. For the SPCC/SUS FSSW joint, the lower SUS sheet material was pulled upward and mixed into the upper SPCC sheet material as layers (Figure 4(c)). On the other hand, for the SUS/SPCC FSSW joint, a small portion of SPCC in the lower sheet was pulled upward into the SUS in the upper sheet and relatively little mechanical mixing occurred between the SPCC and the SUS (Figure $4(\mathrm{~d})$ ). The result of a line scan of the $\mathrm{Cr}$ content along the interface of the region $\mathrm{R} 1$ confirms the mechanical mixing between the SPCC and SUS as shown in Figure 4(e).

The orientation maps of the stir zone underneath the root of the pin $\left(R_{s}\right.$ in Figure 3 and similar locations for FSSW joints of other material combinations) show that considerably finer homogeneous grains developed in the stir zone in comparison with the base materials as shown in Figures 5(a)-5(f). The average grain size of the base material was approximately $13.2 \mu \mathrm{m}$ for SPCC and $27.4 \mu \mathrm{m}$ for SUS. Note that the grain sizes of the stir zone differed somewhat among the four different material combinations. The average grain size of the stir zone of the SPCC/SPCC joint, $10.74 \mu \mathrm{m}$, was somewhat larger than that of the SUS/SUS joint, $6.89 \mu \mathrm{m}$. This may be explained by the different phase transformation temperatures of the base materials. A further discussion on the phase transformation of the base materials during FSSW is beyond the scope of the present study and will be discussed elsewhere.

It is interesting to note that the texture of dissimilar FSSW joints strongly depends on the upper sheet material. Even though the $8.76 \mu \mathrm{m}$ average grain size of the SPCC/SUS joint is only slightly larger than that of the SUS/SPCC joint, $8.39 \mu \mathrm{m}$, as shown in Figures 5(e) and 5(f), the texture of the 


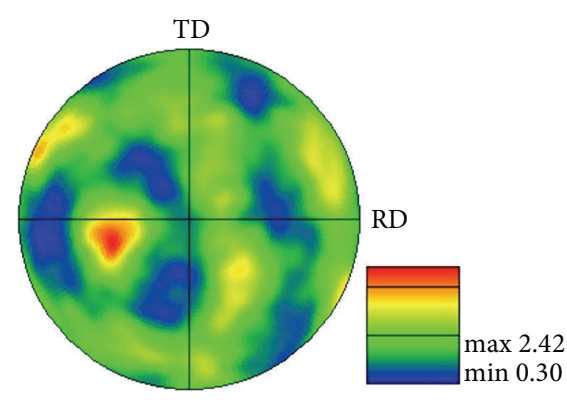

(a)

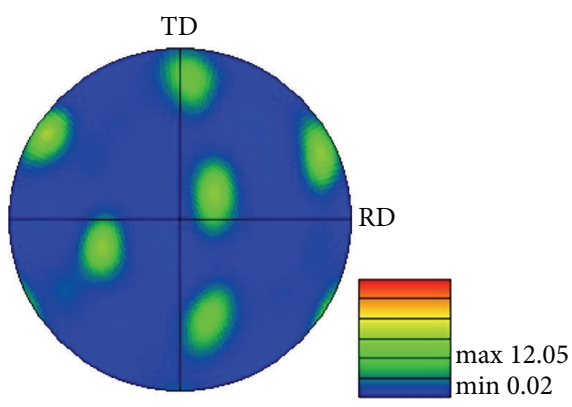

(c)

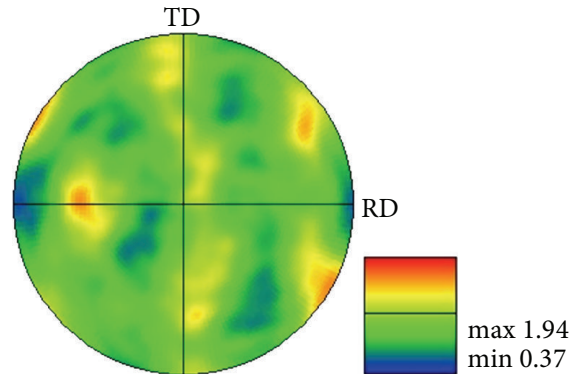

(b)

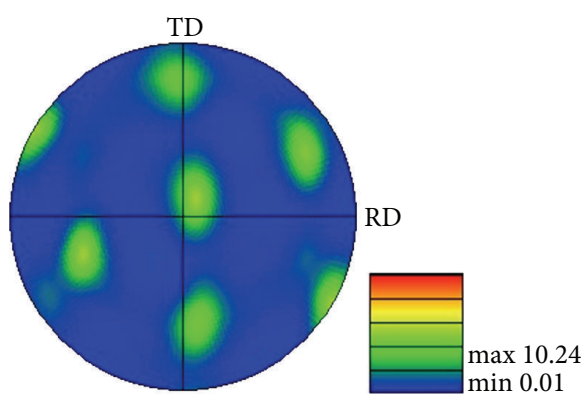

(d)

FIGURE 6: Pole figures of the stir zone in (a) SPCC/SPCC, (b) SPCC/SUS, (c) SUS/SPCC, and (d) SUS/SUS, respectively; RD and TD correspond to rolling and transversal directions, respectively.

stir zone of the SPCC/SUS joint is almost random (a very weak shear texture) and differs considerably from that of the SUS/SPCC joint as shown in Figures 6(b) and 6(d). In the stir zone of the SUS/SPCC joint, a clear shear texture developed, similar to the texture of the SUS/SUS joint as shown in Figures 6(c) and 6(d). The dependence of the microstructural characteristics on the upper sheet material is probably due to that only the upper sheet material contacts the tool directly during most of the FSSW process.

Hardness profiles were made with a spacing of $0.3 \mathrm{~mm}$ along three parallel lines: two lines in the upper sheet and one line in the lower sheet (Figure 7(a)); these profiles were collected for FSSW joints of each of the four material combinations tested (Figures 7(b)-7(e)). The hardness profiles in Figures 7(b)-7(e) show typical hardness distributions across the base metal, the heat affected zone (HAZ), and the stir zone. The hardness of the stir zone is generally higher than that of the base metal for both SPCC and SUS due to the large plastic deformation and fine-grained microstructure in the stir zone [22]; a slight decrease of the hardness in the HAZ is also observed.

3.2. Mechanical Behavior under Combined Loads. Loaddisplacement curves for FSSW joints of four different material combinations at four different loading angles clearly show that the maximum failure load and toughness of the joints depend on the material combinations and loading angles (Figure 8); the maximum load decreases as the loading angle increases for all material combinations studied as listed in Table 3. This tendency of the maximum load is similar to that
TABLE 3: The quasi-static failure loads of the FSSW joints under various loading conditions.

\begin{tabular}{lcccc}
\hline \multirow{2}{*}{$\begin{array}{l}\text { Loading } \\
\text { angle }\left(^{\circ}\right)\end{array}$} & SPCC/SPCC & SPCC/SUS & SUS/SPCC & SUS/SUS \\
\hline 0 & $7.81(0.095)$ & $8.42(0.060)$ & $8.60(0.230)$ & $10.00(0.201)$ \\
15 & $7.70(0.032)$ & $7.75(0.008)$ & $6.54(0.183)$ & $8.81(0.283)$ \\
22 & $7.40(0.077)$ & $7.60(0.062)$ & $6.43(0.220)$ & $8.43(0.092)$ \\
30 & $6.93(0.060)$ & $7.40(0.073)$ & $6.10(0.090)$ & $8.30(0.052)$ \\
\hline
\end{tabular}

${ }^{*}$ Average of the results of two FSSW specimens; values in the parentheses are the standard deviations.

observed in RSW experiments reported by Lin et al. [18] and Song and Huh [20].

Under a pure opening load $\left(\phi=0^{\circ}\right)$, failure occurred by a typical nugget pullout mode. By contrast, under a combined load, the joint's failure initiated with a nugget rotation due to the shear component of the combined load, followed by complete separation of the upper sheet by tearing off from the joint. A comparison of the top and bottom views of the completely separated SPCC/SPCC FSSW joints under a pure opening load $\left(\phi=0^{\circ}\right.$, Figures 9 (a) and 9(b)) and a combined load of $\phi=30^{\circ}$ (Figures 9(c) and 9(d)) shows that nugget rotation occurred under the combined load (Figures 9(c) and $9(\mathrm{~d})$ ), while a typical nugget pullout fracture occurred under the pure opening load (Figures 9(a) and 9(b)). As shown in Figure $9(\mathrm{~d})$, the upper sheet was torn off at the final stage of the failure as the rupture propagated along the circumference of the nugget. A similar failure mechanism was observed for 


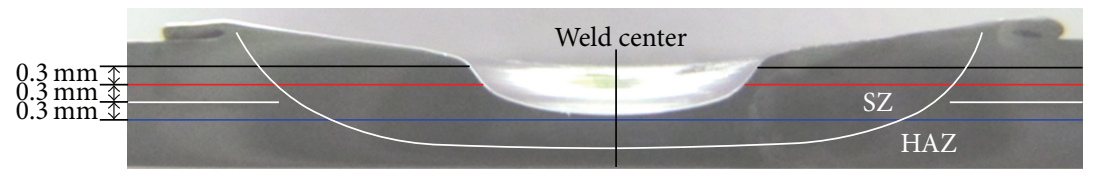

(a)

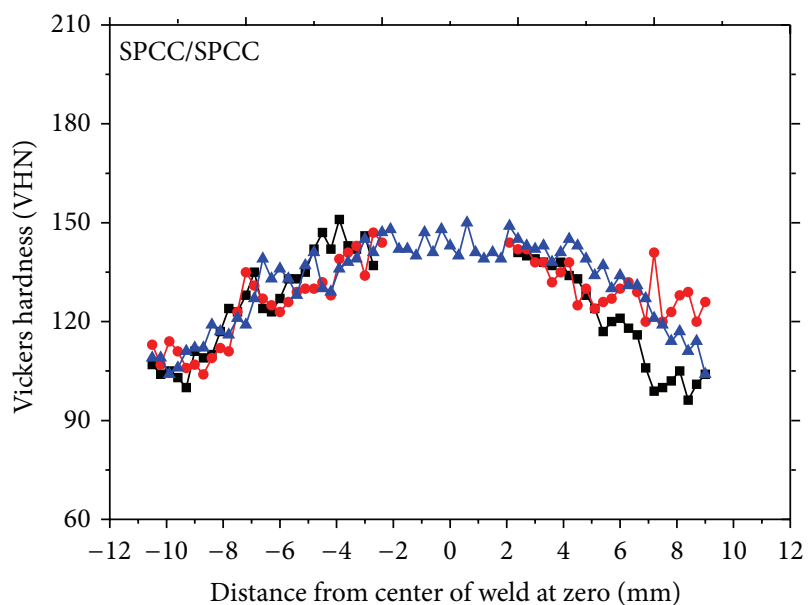

(b)

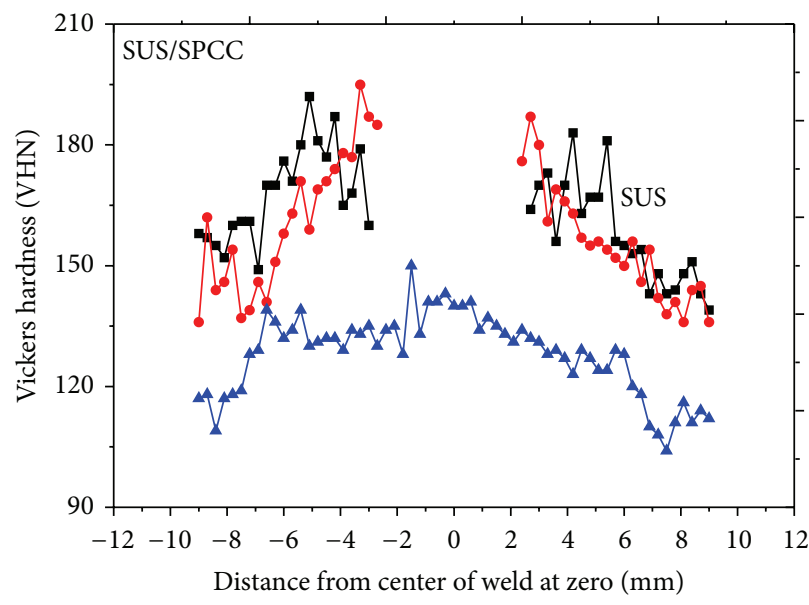

(d)

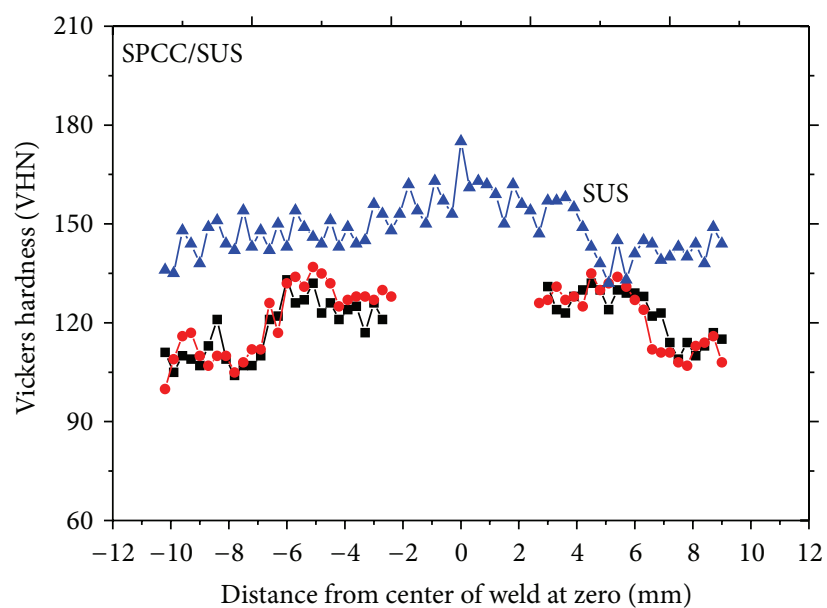

(c)

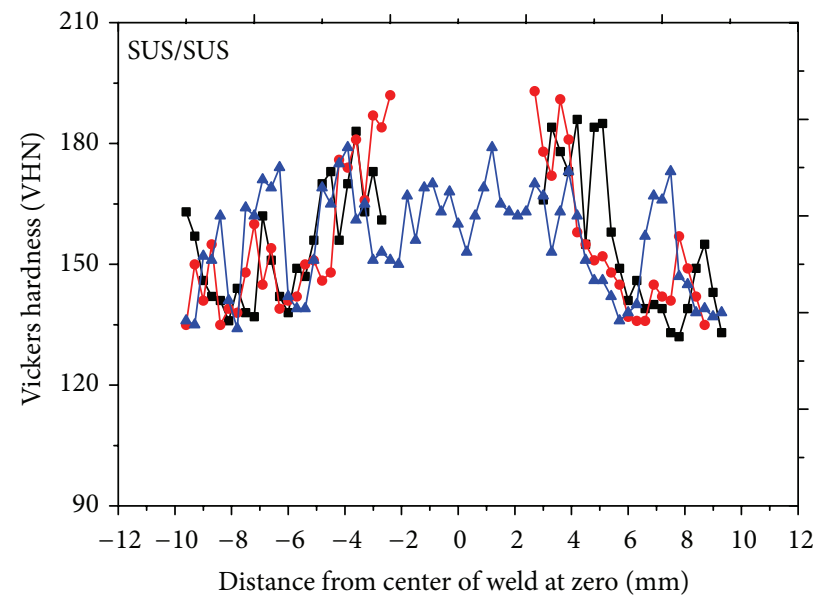

(e)

FIGURE 7: (a) Locations of the three parallel hardness traverses for a SPCC/SPCC joint; hardness profiles of FSSW joint cross sections, showing typical hardness distributions across the base metal, the HAZ, and the stir zone: (b) SPCC/SPCC, (c) SPCC/SUS, (d) SUS/SPCC, and (e) SUS/SUS.

RSW by Lin et al. [18], Song and Huh [20], and Song et al. [23].

The cross-sectional optical micrograph of a completely failed SPCC/SPCC FSSW joint under a pure opening load $\left(\phi=0^{\circ}\right)$ shows that the typical nugget pullout failure occurred by uniform necking/shear along the circumferential boundary of the nugget as shown in Figure 10(a). The crosssectional optical micrograph of a completely failed FSSW joint under a combined load of $\phi=22^{\circ}$ (Figure 10(b)) shows that the failure of the joint under a combined load was initiated by necking and shear at the stretching side with respect to the shear component of the load (marked as A in Figure 10(b)), even though signs of necking are also observed on the opposite side. The rupture then propagated along the circumference of the weld nugget. Finally, the upper sheet was completely torn off from the lower sheet at nearly the opposite side from the location where the rupture initiated (marked as B in Figure 10(b)). The failures of FSSW joints for the material combinations of SPCC/SUS, SUS/ SPCC, and SUS/SUS and at different combined loading angles $\phi=15^{\circ}$ and $30^{\circ}$ were quite similar to the result shown in Figure 10 and not shown here.

The maximum loads under combined loads were simply decomposed into the axial and shear components using (1) for the four different material combinations. A failure contour then can be constructed in terms of the axial and shear load. Several failure criteria have been proposed to describe the failure of RSW under combined loads. Lee et al. [17] proposed 


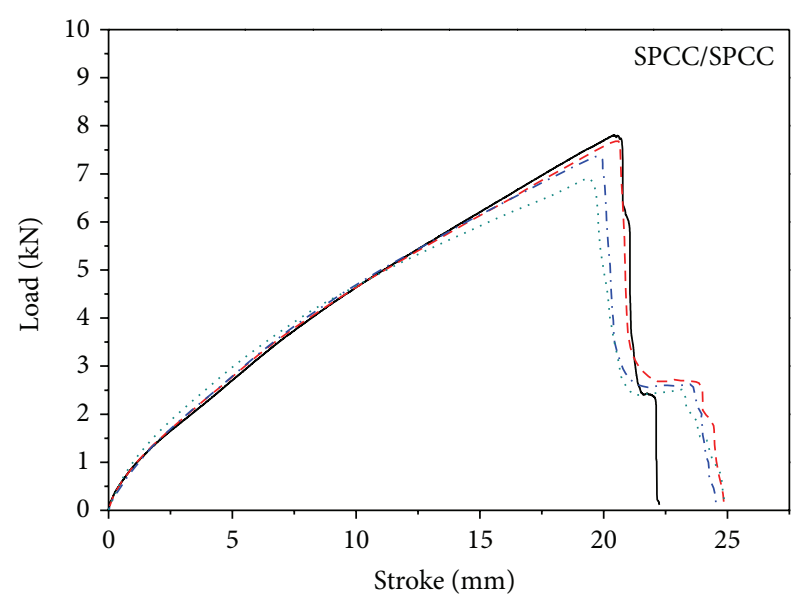

(a)

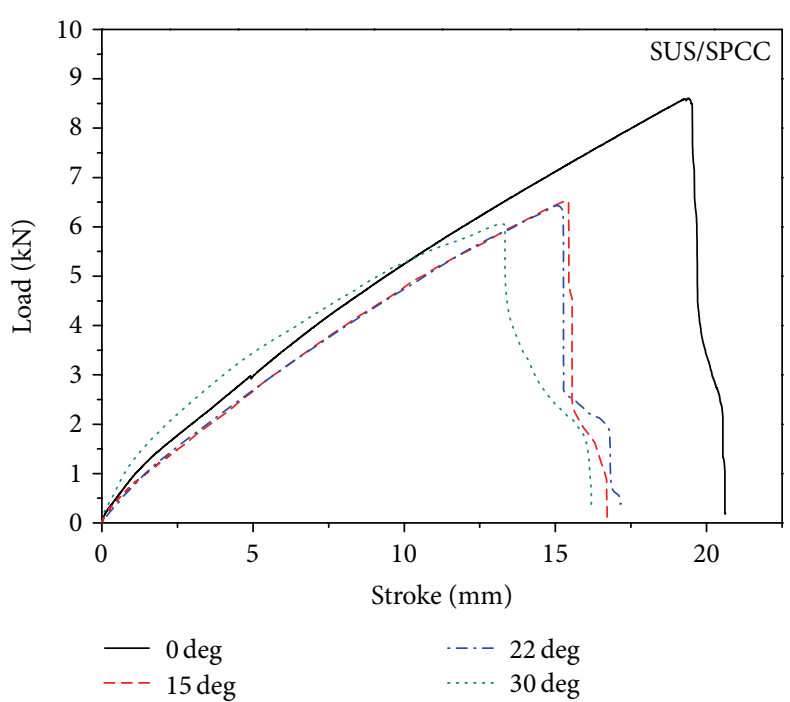

(c)

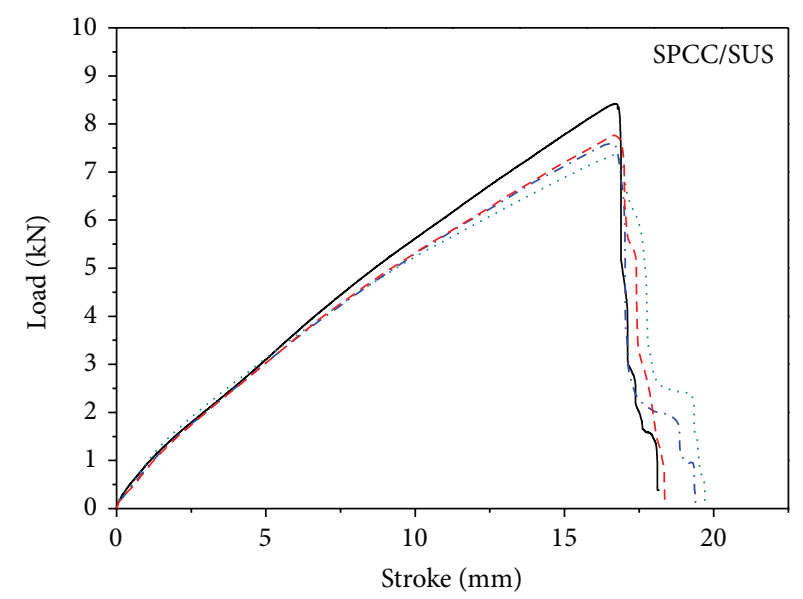

(b)

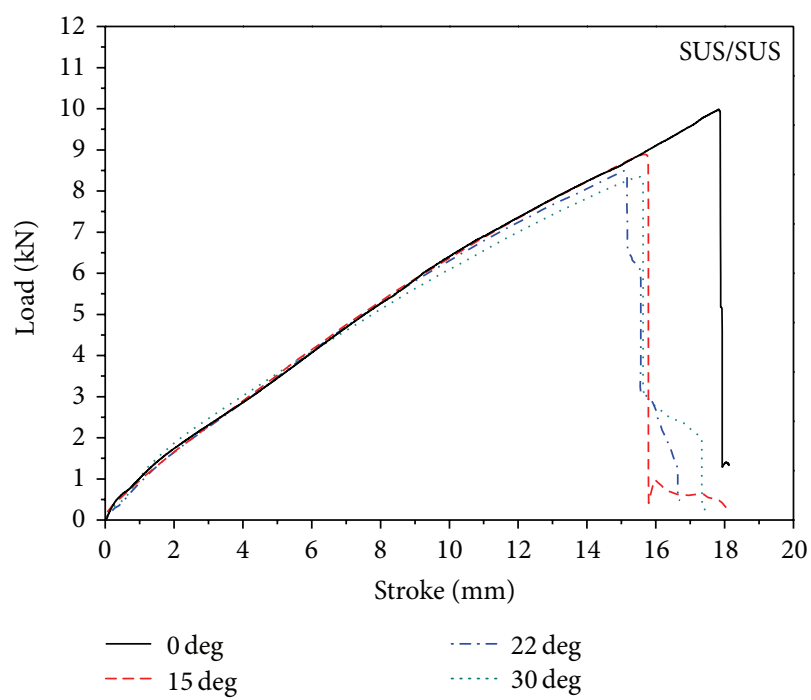

(d)

FIGURE 8: Load-displacement curves for FSSW joints of (a) SPCC/SPCC, (b) SPCC/SUS, (c) SUS/SPCC, and (d) SUS/SUS at four different loading angles.

a failure criterion based on the normal and shear failure loads of the weld, which were determined under pure opening and shear loads, respectively. Under combined loads, they proposed the following failure criterion:

$$
\left(\frac{F_{n}}{F_{N}}\right)^{n}+\left(\frac{F_{s}}{F_{S}}\right)^{n}=1,
$$

where $F_{n}$ and $F_{s}$ are the applied normal and shear loads, respectively, $F_{N}$ and $F_{S}$ are the normal and shear failure loads of the spot weld, respectively, and $n$ is the fitting parameter. In general, $n$ is set to 2 to fit the experimental results.

Lin et al. [18] proposed an engineering failure criterion in terms of the axial and shear loads with consideration of the sheet thickness and the nugget radius under combined loads.
Their failure criterion, based on the lower bound analysis under combined opening and shear loads, is expressed as

$$
\begin{aligned}
& {\left[1-2 \alpha+2 \alpha^{2}\right]\left(\frac{F_{n}}{2 \pi r t \tau_{0}}\right)^{2}} \\
& \quad+\left[\frac{1}{3}+\left(\frac{4 t}{2 \pi r}\right)\right]\left(k \frac{F_{s}}{2 \pi r t \tau_{0}}\right)^{2}=1,
\end{aligned}
$$

where $\tau_{0}$ is the shear yield strength, $\alpha$ is the loading parameter, and $k$ is the fitting constant. For a combined load, $\alpha=0.5$ is used for square-cup specimens [18].

Recently, Song and Huh [20] also proposed a failure criterion to describe the failure behavior of RSW joints under combined loads:

$$
\left(\frac{F_{n}}{F_{N}}\right)^{2}+\beta\left(\frac{F_{n}}{F_{N}}\right)\left(\frac{F_{s}}{F_{S}}\right)+\left(\frac{F_{s}}{F_{S}}\right)^{2}=1 .
$$




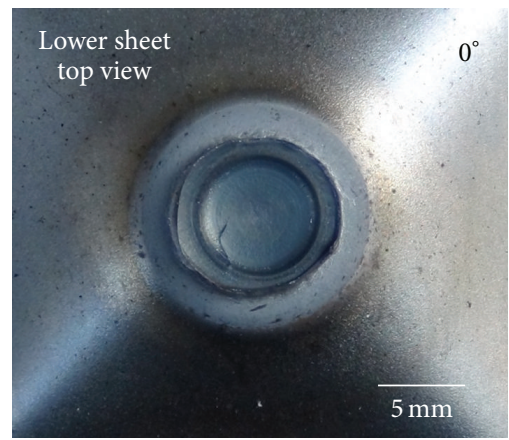

(a)

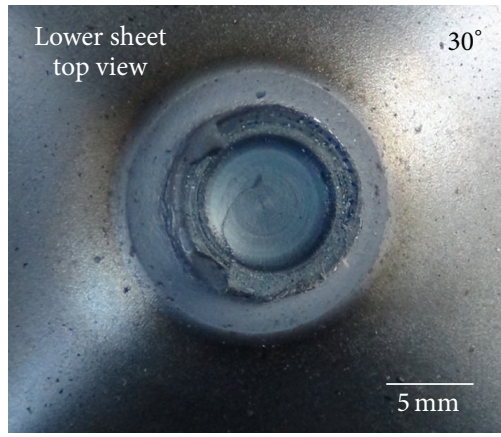

(c)

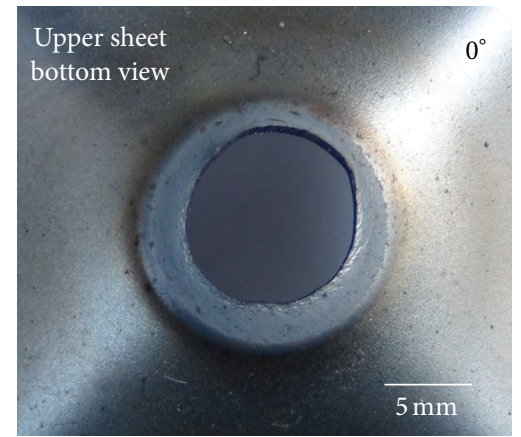

(b)

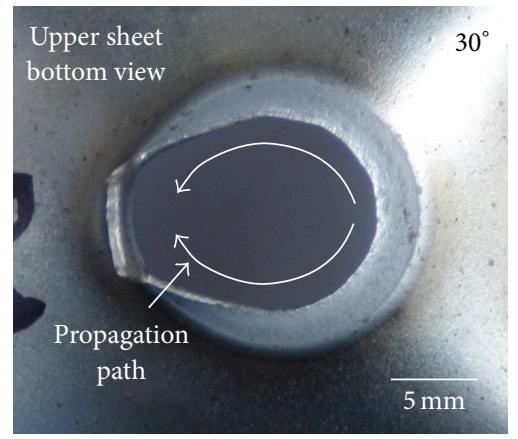

(d)

FIGURE 9: Top and bottom views of the completely separated SPCC/SPCC FSSW joints under ((a), (b)) a pure opening load $\left(\phi=0^{\circ}\right)$ and $((\mathrm{c})$, (d)) a combined load of $\phi=30^{\circ}$, respectively.

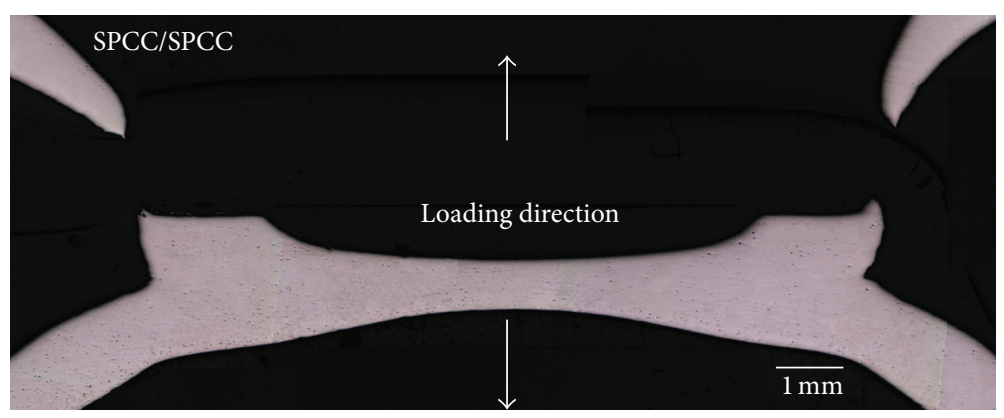

(a)

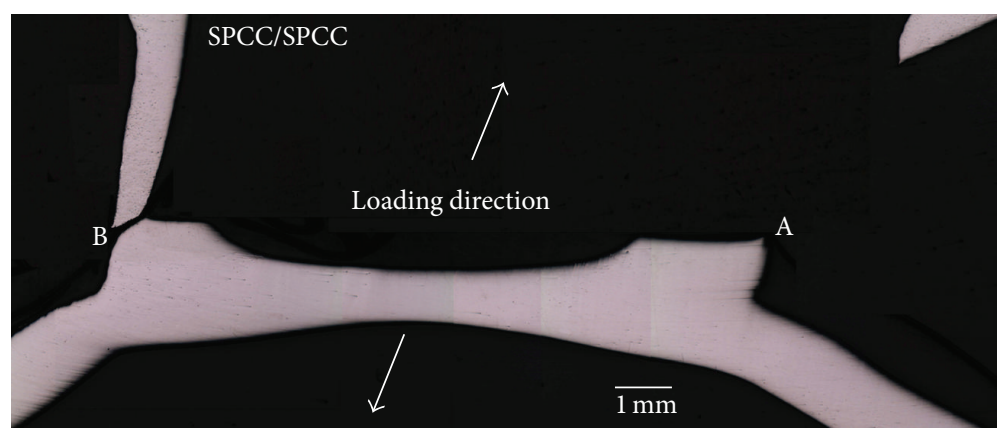

(b)

Figure 10: Cross-sectional macrographs of completely failed SPCC/SPCC FSSW joints under (a) a pure opening load $\left(\phi=0^{\circ}\right)$ and $(\mathrm{b})$ a combined load of $\phi=22^{\circ}$, respectively. 


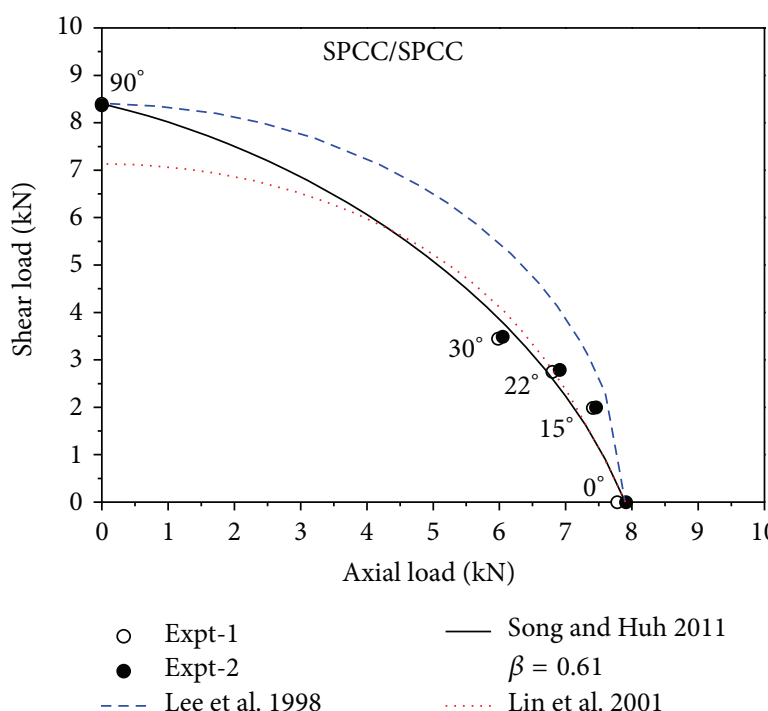

(a)

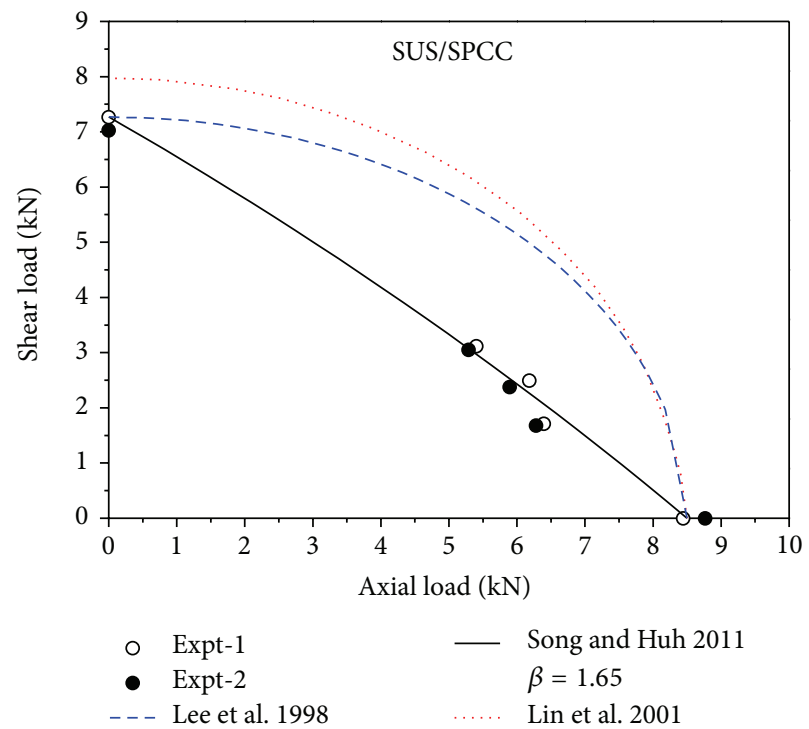

(c)

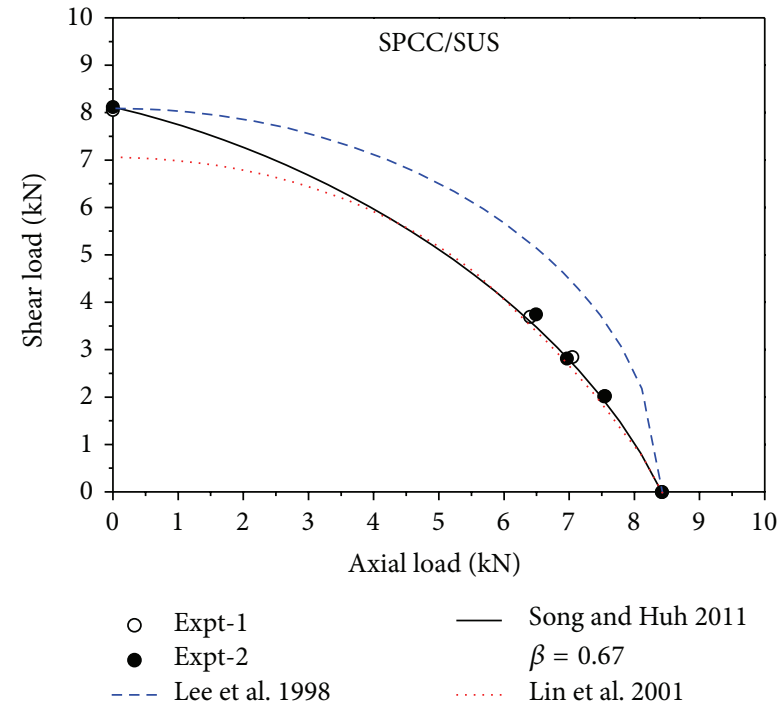

(b)
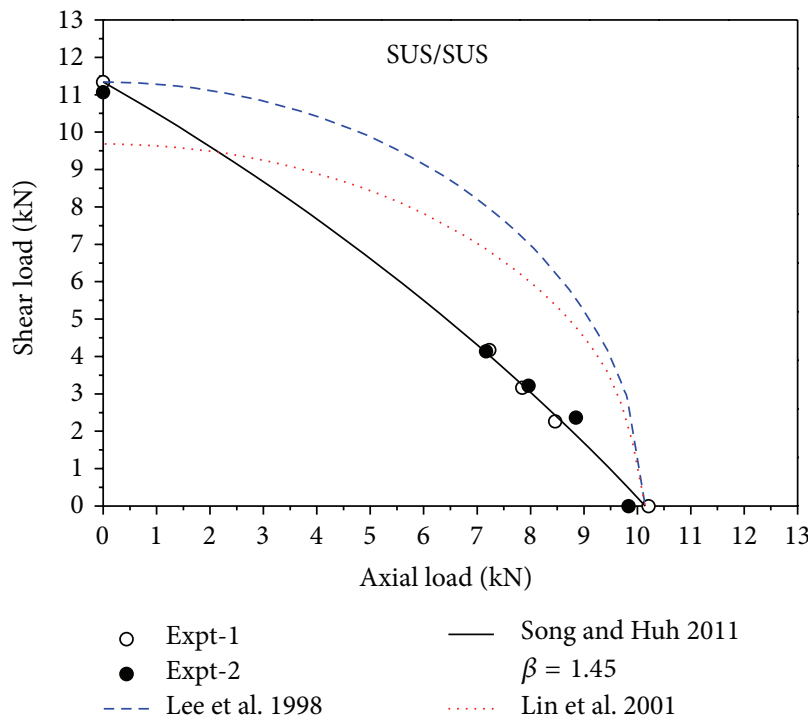

(d)

FIGURE 11: Comparison of the experimental result with conventional failure criteria: (a) SPCC/SPCC, (b) SPCC/SUS, (c) SUS/SPCC, and (d) SUS/SUS.

Here, again, $F_{N}$ and $F_{S}$ are the normal and shear failure loads of the spot weld, respectively. The variable $\beta$ is the failure parameter that can be obtained by least-squares fitting to minimize the discrepancy between the experimental result and the interpolated one. The shape of the failure curve is elliptic when $\beta=0$, and in this condition is identical to the failure criterion proposed by Lee et al. [17].

Based on the experimental results and above mentioned failure criteria, failure contours for FSSW joints under combined loads were constructed in terms of the axial and shear loads for each of the four different material combinations (Figure 11). Note that in constructing the failure contours, the experimental result of lap-shear specimens [21] was used as the shear failure load $F_{S}$. Also note that for the failure contours of dissimilar FSSW joints based on (3), the shear yield strength of the upper sheet material was used since the fracture mainly occurred in the upper sheet material. Comparison of the failure contours suggests that the failure criterion proposed by Lee et al. [17] is inadequate to describe the failure of FSSW joints under opening-dominant combined loads. Although the experimental result of FSSW joints with SPCC on the upper sheet (Figures 11(a)-11(b)) is relatively consistent with the failure criterion suggested by Lin et al. [18], the experimental result of FSSW joints with SUS on the upper sheet (Figures 11(c)-11(d)) does not agree well with that criterion. On the other hand, the experimental results for all four different material combinations can agree well with the failure criterion proposed by Song and Huh [20] by selecting 


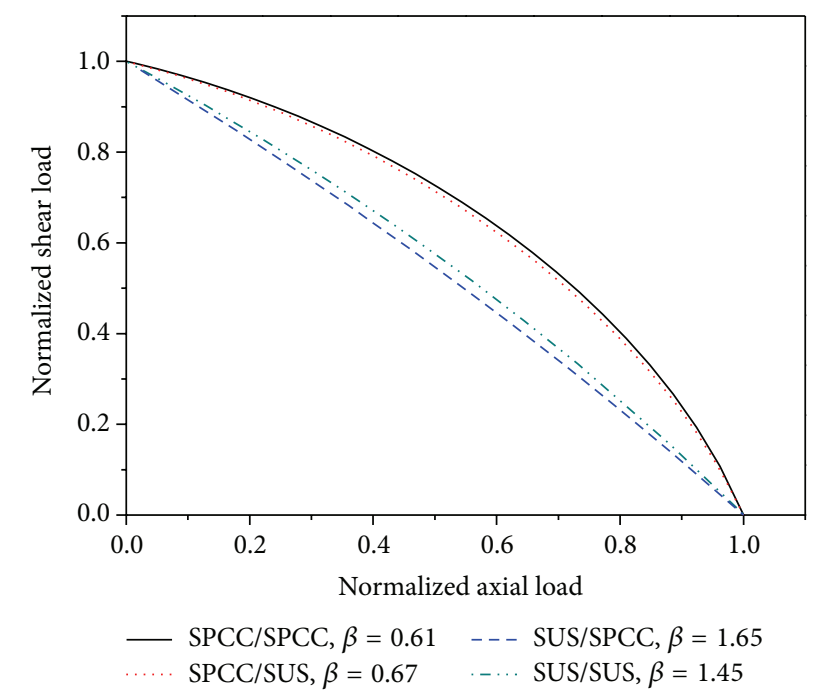

FIGURE 12: Normalized failure contours for the FSSW joints with four different material combinations based on the failure criterion of Song and Huh [20].

different values of $\beta$. It is interesting to note that the value of $\beta$ strongly depends on the material on the upper sheet of the joint; the FSSW joints with a softer and more ductile material on the upper sheet (SPCC/SPCC and SPCC/SUS) have considerably lower values of $\beta$. Actually, comparison of the failure contours based on Song and Huh [20] in terms of the normalized axial and shear loads, which were normalized by the corresponding normal (pure opening, $\phi=$ $\left.0^{\circ}\right)$ and shear $\left(\phi=90^{\circ}\right)$ failure loads, respectively, confirms the dependence of the failure contours on the upper sheet material (Figure 12). The shape of the failure contours is close to elliptic with SPCC as the upper sheet, while the failure contours take the form of a relatively straight line with SUS as the upper sheet.

\section{Conclusions}

Mechanical behaviors of FSSW joints of two dissimilar ferrous alloys under opening-dominant combined loads were experimentally investigated. Defect-free spot joints were successfully fabricated with four different material combinations. EBSD analysis shows that extremely fine homogeneous grains developed in the stir zone, while the texture of dissimilar FSSW joints depends on the upper sheet material. The failure contours for the FSSW joints under combined loads were constructed in terms of the axial load and shear load by modifying existing failure criteria for RSW. The shape of the failure contour also depends on the upper sheet material. The failure contours are nearly elliptic in shape when the upper sheet is SPCC and are relatively straight lines when the upper sheet is SUS. The results of the present study also suggest that the mechanical and material properties of FSSW joints of dissimilar ferrous alloys are improved when the lap joint is designed with the "harder" material on the bottom and the "softer" material on top.

\section{Conflict of Interests}

The authors declare that there is no conflict of interests regarding the publication of this paper.

\section{Acknowledgments}

This research was financially supported by the Ministry of Education (MOE) and National Research Foundation of Korea (NRF) through the Human Resource Training Project for Regional Innovation. Michael Miles acknowledges support from National Science Foundation Grant CMMI1131203. H.-H. Cho and H. N. Han were supported by Basic Science Research Program through the National Research Foundation of Korea (NRF) and funded by the Ministry of Science, ICT, and Future Planning (2013008806).

\section{References}

[1] W. M. Thomas, E. D. Nicholas, J. C. Needham, P. Temple-smith, S. W. K. W. Kallee, and C. J. Dawes, "Friction stir welding," UK Patent Application GB 2306366 A, 1991.

[2] W. Yuan, R. S. Mishra, S. Webb et al., "Effect of tool design and process parameters on properties of Al alloy 6016 friction stir spot welds," Journal of Materials Processing Technology, vol. 211, no. 6, pp. 972-977, 2011.

[3] D.-A. Wang and S.-C. Lee, "Microstructures and failure mechanisms of friction stir spot welds of aluminum 6061-T6 sheets," Journal of Materials Processing Technology, vol. 186, no. 1-3, pp. 291-297, 2007.

[4] E. Folkhard, Welding Metallurgy of Stainless Steels, Spring, New York, NY, USA, 1988.

[5] O. P. Khanna, Welding Technology, Dhanpat Rai Publications, New Delhi, India, 16th edition, 2007.

[6] Z. Feng, M. L. Santella, S. A. David et al., "Friction Stir Spot Welding of Advanced High-Strength Steels -A Feasibility Study, SAE World Congress, Detroit, Mich, USA, 2005.

[7] S. W. Baek, D.-H. Choi, C.-Y. Lee et al., "Structure-properties relations in friction stir spot welded low carbon steel sheets for light weight automobile body," Materials Transactions, vol. 51, no. 2, pp. 399-403, 2010.

[8] Y. Hovanski, M. L. Santella, and G. J. Grant, "Friction stir spot welding of hot-stamped boron steel," Scripta Materialia, vol. 57, no. 9, pp. 873-876, 2007.

[9] M. P. Miles, C. S. Ridges, Y. Hovanski, J. Peterson, M. L. Santella, and R. Steel, "Impact of tool wear on joint strength in friction stir spot welding of DP 980 steel," Science and Technology of Welding and Joining, vol. 16, no. 7, pp. 642-647, 2011.

[10] Y. F. Sun, H. Fujii, N. Takaki, and Y. Okitsu, "Microstructure and mechanical properties of mild steel joints prepared by a flat friction stir spot welding technique," Materials and Design, vol. 37, pp. 384-392, 2012.

[11] Y. J. Chao, "Ultimate strength and failure mechanism of resistance spot weld subjected to tensile, shear, or combined tensile/shear loads," Journal of Engineering Materials and Technology, Transactions of the ASME, vol. 125, no. 2, pp. 125-132, 2003.

[12] P. Wung, "A forced-based failure criterion for spot weld design," Experimental Mechanics, vol. 41, no. 1, pp. 107-113, 2001. 
[13] P. Wung, T. Walsh, A. Ourchane, W. Stewart, and M. Jie, "Failure of spot welds under in-plane static loading," Experimental Mechanics, vol. 41, no. 1, pp. 100-106, 2001.

[14] D. Radaj, "Stress singularity, notch stress and structural stress at spot-welded joints," Engineering Fracture Mechanics, vol. 34, no. 2, pp. 495-506, 1989.

[15] D. Radaj and S. Zhang, "On the relations between notch stress and crack stress intensity in plane shear and mixed mode loading," Engineering Fracture Mechanics, vol. 44, no. 5, pp. 691704, 1993.

[16] S. Zhang, "Approximate stress formulas for a multiaxial spot weld specimen," Welding Journal, vol. 80, no. 8, pp. 201s-203s, 2001.

[17] Y.-L. Lee, T. J. Wehner, M.-W. Lu, T. W. Morrissett, and E. Pakalnins, "Ultimate strength of resistance spot welds subjected to combined tension and shear," Journal of Testing and Evaluation, vol. 26, no. 3, pp. 213-219, 1998.

[18] S.-H. Lin, J. Pan, S.-R. Wu, T. Tyan, and P. Wung, "Failure loads of spot welds under combined opening and shear static loading conditions," International Journal of Solids and Structures, vol. 39, no. 1, pp. 19-39, 2001.

[19] S.-H. Lin, J. Pan, T. Tyan, and P. Prasad, "A general failure criterion for spot welds under combined loading conditions," International Journal of Solids and Structures, vol. 40, no. 21, pp. 5539-5564, 2003.

[20] J. H. Song and H. Huh, "Failure characterization of spot welds under combined axialshear loading conditions," International Journal of Mechanical Sciences, vol. 53, no. 7, pp. 513-525, 2011.

[21] M. A. M. Hossain, M. T. Hasan, S. T. Hong, M. Miles, H. H. Cho, and H. N. Han, "Failure behaviors of friction stir spot welded joints of dissimilar ferrous alloys under quasi-static shear loads," International Journal of Materials and Product Technology, vol. 48, no. 1-4, pp. 179-193, 2014.

[22] Y. Miyano, H. Fujii, Y. Sun, Y. Katada, S. Kuroda, and O. Kamiya, "Mechanical properties of friction stir butt welds of high nitrogen-containing austenitic stainless steel," Materials Science and Engineering A, vol. 528, no. 6, pp. 2917-2921, 2011.

[23] J. H. Song, H. Huh, J. H. Lim, and S. H. Park, "Effect of tensile speed on the failure load of a spot weld under combined loading conditions," International Journal of Modern Physics B, vol. 22, no. 9-11, pp. 1469-1474, 2008. 

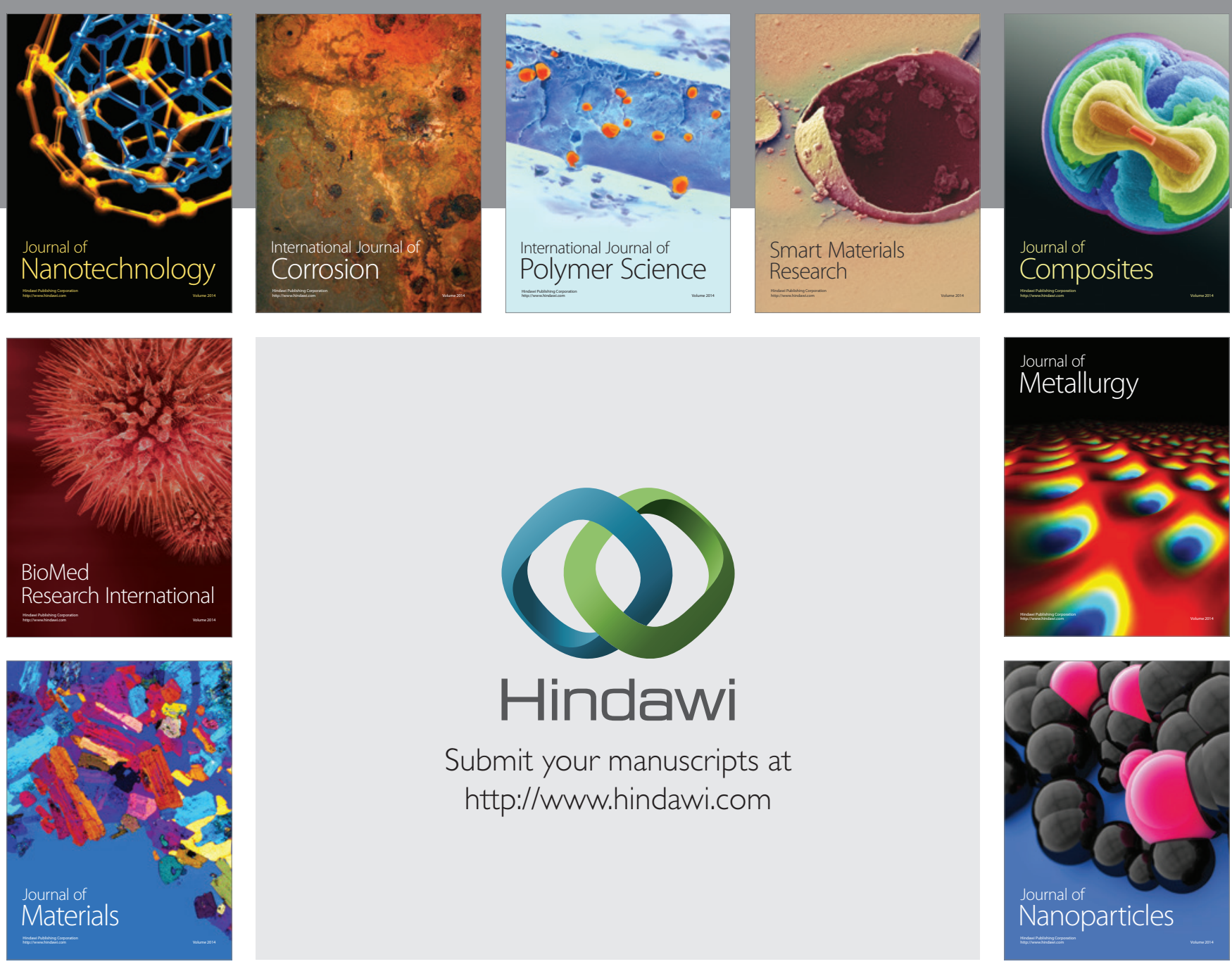

Submit your manuscripts at http://www.hindawi.com
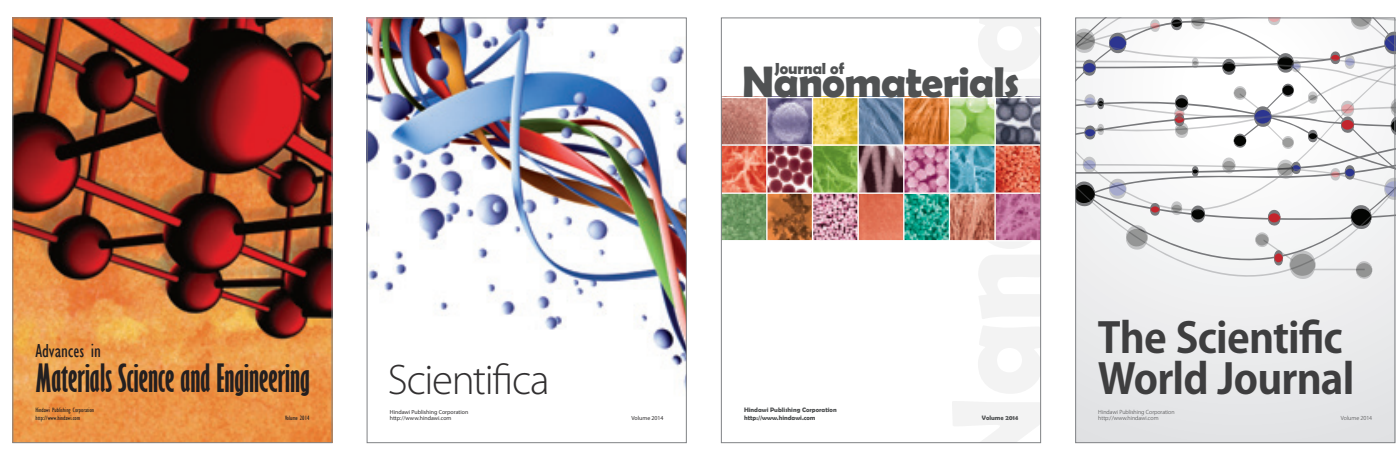

\section{The Scientific World Journal}
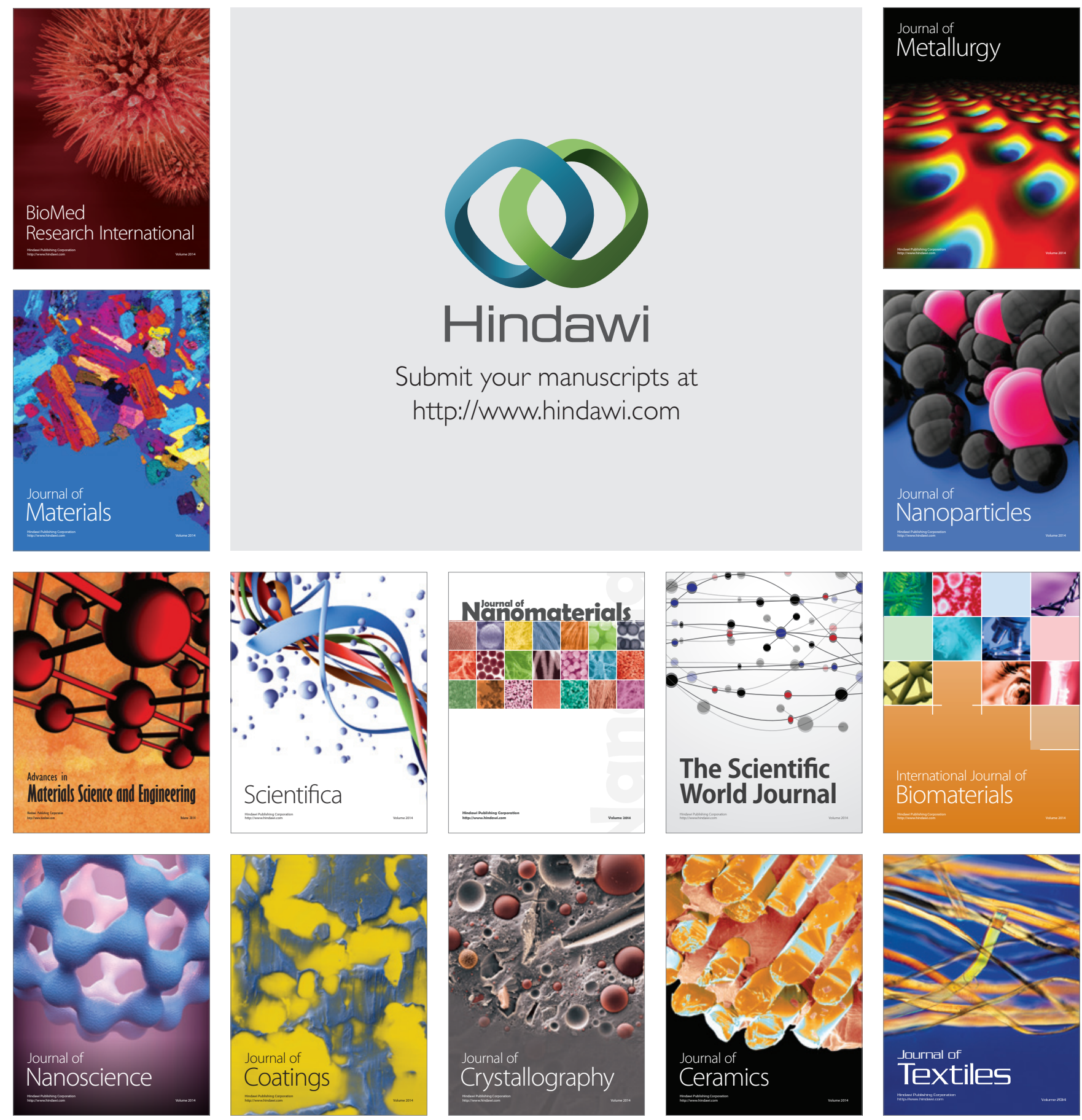